
\title{
R Reserach S Suare \\ The Health-trash Nexus in Challenging Environments: A Spatial Mixed Methods Analysis of Accra, Ghana
}

\section{Sandra Owusuaah Bempah ( $\nabla$ sbempah@kent.edu )}

Kent State University https://orcid.org/0000-0002-5374-2951

\section{Andrew Curtis}

Case Western Reserve University School of Medicine

\section{Gordon Awandare}

University of Ghana

Jayakrishnan Ajayakumar

Case Western Reserve University School of Medicine

Nancy Nyakoe

University of Ghana

\section{Research}

Keywords: trash, drain, SVG, health

Posted Date: August 3rd, 2021

DOl: https://doi.org/10.21203/rs.3.rs-757498/v1

License: (9) This work is licensed under a Creative Commons Attribution 4.0 International License.

Read Full License

Version of Record: A version of this preprint was published at Applied Geography on June 1st, 2022. See the published version at https://doi.org/10.1016/j.apgeog.2022.102701. 


\section{Abstract}

Background: Increasing urbanization in Ghana has led to a waste management crisis with multiple public health consequences. The contextualized mapping of what is dumped, where and why might provide vital on-the-ground support to address the problem itself, as well as the spillover disease impacts. One of the biggest challenges, however, are the required spatial and temporal granular data.

Methods: In this paper, we employ a spatial mixed methods approach to investigate the issue of waste management through the lens of health and disparity in Teshie, a suburb of Accra, Ghana. Environmental health risks digitized and mapped from these data sources included trash, plant overgrowth, drains and stagnant water.

Results: There was an overlaying relationship between trash and open drains. Open drains encouraged the indiscriminate disposal of trash and also served as a cheaper alternative to paying for waste pick up. Poverty played an intricate role in influencing a trash disposal complex at the sub-neighborhood scale.

Conclusion: The trash situation in Teshie is a complex one with varied levels of risks for infectious diseases.

\subsection{Introduction}

Subject A:

"But after that, people kept dumping rubbish and going to toilet in the gutter. Sometimes people try to discourage those who do that by throwing stones at them. And yet people still find means of throwing rubbish and toilet in the gutter".

Yes. When people throw rubbish or go to toilet in the gutter, the boys who used to clean it up will be throwing stones at them. But the obstinate nature of community members I think deterred them. That is why the gutter is now so dirty.

Because of the gutter and the dirty seashore where the kids go to play all the time, that contributes to we are being sick all the time. Some kids will be defecating in the gutter and at the same time playing in it. So, it also contributes to it. We are really suffering.

Trash accumulation in many developing world urban centers poses a variety of health risks. This is especially true for settlements on "unofficial" land where dramatic population increases are matched with little to no provision of sanitation services, which in turn results in a haphazard waste disposal approach. This not only reduces local quality of life but can lead to a variety of health problems (Triassi et al., 2015) for example rats scavenge on discarded food items leading to the risk of leptospirosis (A. Krystosik et al., 2020; M.T et al., 2019; Muñoz-Zanzi et al., 2014), or mosquitoes breed in water trapped in plastic containers increasing local malaria risk (Addo et al., 2017; Kiddy-Kodua et al., 2018; A. Krystosik et al., 2020), and feces can contaminate local water sources leading to enteric disease outbreaks (Boadi \& 
Kuitunen, 2002; Prüss-Ustün et al., 2019). Yet while these interconnections (what we will refer to as the trash complex in this paper) are often described in the literature, there is still relatively little written from a specific granular geographic context. As the opening quote shows, the implications of illegal dumping on local health, especially the impact it can have on children are significant. In this paper we will advance this literature by considering this complexity for different communities in a suburb of Accra, Ghana, viewed through the lens of a contextualized spatial perspective. The rationale for such an approach is that to be able to map trash at a fine enough temporal and spatial scale in challenging environments could be useful in helping explain localized health risks while also informing response strategies, especially during disease outbreaks. However, to do this effectively also requires an associated contextualized layer incorporating on-the-ground insight explaining why trash occurs where it does, what the immediate health consequences are, and what can be done in response. In this paper we present results from this type of contextualized mapping of the trash complex.

\subsection{Background}

Trash disposal in informal settlements where official service provision is often absent is a global problem (Asase et al., 2009). For impoverished communities with official trash removal options, even when heavily subsidized by the government, some might still prefer the no cost option of dumping in hidden and nonpoliced spaces (Matheson, 2019; Tadesse et al., 2008). This situation also occurs, or is worsened when there is local unhappiness in the management of "official" trash removal services (Addai \& DansoAbbeam, 2014; Amoah, 2018). One such problem being the perceived issue of corruption (Bukari et al., 2017). As a result trash disposal is often highly heterogeneous, including burning, burying or the illegal dumping in any available space such as the alleys between houses, on open ground, or in the drains designed to carry away excess water and sewage (Bempah et al., 2020; Safo-adu et al., 2019). For example, Accra, Ghana, the setting for this study, it is estimated that waste management companies only collect about $60 \%$ of the daily generated waste. The remaining $40 \%$ end up in drains, open spaces, water bodies (Boadi \& Kuitunen, 2002), or is disposed of using other means such as burning or burying (Safoadu et al., 2019). Unfortunately this can lead to various localized health risks that can be directly traced to the "trash cycle", including diseases spread by vermin, flies, mosquitoes, or contamination of local water systems through the overland spillover or leaching through ground strata (Ashbolt, 2004; Dongzagla et al., 2020). Burning trash can also cause respiratory problems (Matheson, 2019), including potential exposure to harmful chemicals. Communities living on or in the shadow of large dumps are also vulnerable to landslips especially during rains (Ahmed et al., 2018).

The problems caused by dumping can also have indirect consequences on human health, such as the clogging of local drainage systems which can cause or exacerbate flooding (Karley, 2009; Matheson, 2019). Local food sources can also become tainted, which in some studies has led to evidence of gastrointestinal infections being elevated for those living in close proximity to waste management/disposal sites (Giusti, 2009). Research has also highlighted the links between disease and proximity to solid waste and polluted liquid waste in drains (Sheela et al., 2017), with children being particularly vulnerable through direct contact, often playing in the trash or in the drains while also being 
less likely to practice handwashing (Teunis et al., 2016). The population and diversity of various disease vectors also increases with the accumulation of trash (A. Krystosik et al., 2020; Qasim et al., 2020).

The trash-health intersection can also be thought of in terms of geography; where do people live in proximity to such dumping? Where are the children's play spaces? Where, when, and how is flooding exacerbated by trash? In a study conducted by Yoada et al. (2014), most participants interviewed admitted that waste was a contributing factor to infectious disease such as malaria, typhoid and diarrhea in their communities. However, the inability to afford waste management services, and the distance each resident would have to travel to dumpsites, meant that trash would still be dumped locally leading to the potential for enteric disease outbreaks including cholera (Addo et al., 2017; Wang et al., 2018). All the factors mentioned by Yoada and colleagues are mappable. The same is true for mosquito-trash connections; even a simple mapping of cans, drums, and other containers could be used to produce a likely mosquito intensity surface (Focks et al., 1999; Raju AK, 2003) and by overlaying actual homes and activity spaces might then predict dengue and malaria likelihood (Messina et al., 2011; Townes et al., 2013). With enough quality granular data such health risk heterogeneity can be teased out (Bempah et al., 2020), though, of course, acquiring the required data is notoriously difficult for such unofficial settlements (Curtis et al., 2013). While remote sensing and geographic information systems (GIS) have previously been used to identify aspects of waste disposal in Ghana such as where to locate landfills (Singh, 2019), or factors influencing waste disposal decisions (Addo et al., 2017; Tadesse et al., 2008), there is little to no fine scale (meaning the space around where trash is dumped) spatial work that captures the type of contextualized granular mapping that could be used to develop such detailed risk surfaces. Here we address this gap using a mixed spatial methods approach to consider the social and behavioral influences on waste disposal. Spatial video geonarratives (SVGs) were used to obtain local knowledge in the form of environmentally cued "go along" interviews, whilst simultaneously collecting spatialized trash-related data that can be mapped to create operational maps (Ajayakumar et al., 2019; Curtis et al., 2015).

\subsection{Methods}

The purpose of this study is to develop a spatially contextualized understanding of waste disposal practices in a typically data-poor area. The study site, Teshie a suburb of Accra, Ghana was chosen due to generally poor social conditions (Verutes et al., 2012) including associated environmental challenges, such as illegal waste disposal, that has previously been linked to high incidences of infectious disease, especially malaria (Amoatey et al., 2008). Teshie is comprised of several distinct neighborhoods (Fig. 1), each with a locally perceived visual character.

\subsection{Study site}

The participants enrolled in this study included residents, community health workers, nurses and lab workers at the Ledzekuku-Krowor Municipal Assembly (LEKMA) hospital in Teshie. Participating residents had previously had a connection to infantile malaria cases at the LEKMA hospital between 2012 to 2016; 
these individuals were part of an on-going malaria research project at the West African Center for Cell Biology of Infectious Pathogens (WACCBIP), at the University of Ghana, Legon. The participating community health workers, nurses and lab workers were chosen for their constant encounters with community residents and as such were familiar with behavioral, logistical, and environmental factors that contributed to the prevalence of local infectious diseases, particularly malaria.

The initial project goal was focused on understanding the spatial complexity of malaria in Teshie (Bempah et al., 2020), however themes mined from these interviews, and then supported through the mapping of health risks from the spatial video data, suggested there should also be a separate focus on trash. Building on this precursor work, this paper focuses on the specific intersection of trash and the overall health of residents.

Residents of Teshie include petty traders, craftsmen, fishermen, drivers, and a handful employed in industry or the formal sector. Salaries in Teshie are generally low, being barely enough for rent, food and water for themselves and their dependents. However, while the entire area of Teshie seen in Fig. 1, is regarded as having an overall low socio-economic status, there is noticeable geographic variation within the different communities, especially regarding the quality of buildings and their surrounding environments. Some communities such as Agblezaa, Malik, and Tebibiano, have better environments (including disease reducing infrastructure such as concrete covered drains), whereas other communities such as Bukueshie, Mobil, Adoemli, Lascala, Camp 2, Yoomo Specs and Teshie NDC displayed obvious signs of poverty, overflowing dumpsites, choked drains, etc. (Bempah et al., 2020).

The geographic variation in the community environments with immediate relevance to malaria risk has previously been mapped using the spatial video as a data source (Bempah et al., 2020). Visible health risks included trash (tires, plastics, organic waste), plant/grass overgrowth, and different human risk associated activities such as children playing in the dirt. Open drain locations and the trash they contained were also mapped. The result of all these digitized risks was an appreciation of how each community varied in terms of its geographic distribution of environmental risks.

\subsection{Spatial video geonarratives}

While spatial videos (SVs) can provide a detailed granular data source to assess intra-community variation in risk (Bempah et al., 2021), it is still reductionist in terms of only quantifying (or mapping) variations in risk. To fully contextualize the risk in each community requires other approaches. Spatial video geonarratives (SVG)s are "go-along" interviews (Ajayakumar et al., 2019; Bempah et al., 2020; Curtis et al., 2018; Curtis, Curtis, et al., 2019a; Burleson \& Giordano, 2016) that combine a "conversation" with a participant while simultaneously collecting spatially enriched video footage. Normally the participant is given a brief background about the study and then he/she decides where to go, and what to talk about in other words what he/she perceives as being relevant to the topic being discussed and not what the researcher dictates as important (Curtis et al., 2015; Curtis, Curtis, et al., 2019b; Curtis, Tyner, et al., 2019; A. R. Krystosik et al., 2017). Therefore, while the initial focus of this body of work was on malaria risk 
(and described in Bempah et. al. 2020), it soon became evident that the complex role of "trash" went beyond just being a contributing factor to mosquito breeding.

In this paper we further mine these narratives to unpack the health complexities of how trash was described by the subjects. During the interviews, each participant's commentaries were inspired by the sights, sounds, and smells of the environment in which the interview was conducted. While normally sight dominates these senses-inspired descriptions, for these SVGs being proximate to a trash accumulation often led to a description of smells and even what the ground felt like underfoot (shifting, or wet and decomposing). As was described in Bempah et. al. (2020), after the interview the commentary was transcribed (with time stamps preceding each comment) and merged with the associated coordinate (GPS) path extracted from the spatial video (extracted using the Video Player software in Fig. 2). All data merging, querying and initial mapping occurred within Wordmapper (Ajayakumar et al., 2019) which is a bespoke software developed by the project team that merges the transcribed narrative (as a .txt file) and extracted GPS paths (extracted from the videos as .gpx file) as inputs for thematic analysis for each SVG (Fig. 3). The output includes every word or the beginning of a comment being tagged with a coordinate that can be mapped. This means that spatially specific comments, such as describing the proximity of trash to food vendors, can be easily mapped along with their contextual description. A combination of spatial queries (for example what is mentioned within $\mathrm{X}$ meters of every trash dump) and thematic mining of words (for example where are drains and trash mentioned) can be combined with the video visuals for a more in-depth understanding of the topic under investigation (Ajayakumar et al., 2019; Curtis, Tyner, et al., 2019). The output of this includes Keyhole Markup Language (KML) for viewing in Google Earth engine, shapefiles for cartographic analysis in GIS, and Comma Separated Value (CSV).

The Teshie SVGs were mined for environment, human action and sanitation themes, along with general mentions of trash, drainage and poverty, including keywords such as "trash", "gutter(s)", "rubbish", "drain(s)", "drainage", "dirt", "dirty".

A further difference with the previous research was comparing overlapping SVGs simultaneously, meaning where multiple interviewees covered the same space, Geonarrative Search (Fig. 4), was used to tease out spatial theme / keyword patterns across narratives. The input for this were the individual outputs (saved KMLs) of the SVGs from Wordmapper. These combined narratives now being evaluated together, were mined for themes related to human activity and sanitation using the same keywords as before. A sentence was counted as one (1) if these words or their synonyms were present in it. The outputs of the geonarratives search included KML, GIS shapefiles and a word cloud.

By using Wordmapper, and Geonarrative Search, an interactive approach moving from text mining, mapping location, image viewing and a return reading of the narrative was used to gain an understanding of where, why trash occurred, along with also identifying the reasons for geographic variations, temporal variations, and health implications.

\subsection{Results}


A total of twelve (12) SVGs, were analyzed for the study area. Out of these, three (3) were collected by walking and nine (9) by driving. While trash was evident in all the communities, the volume / intensity varied geographically as can be seen in Fig. 5 which displays normalized Thiessen Polygons representing each community. As community boundaries were locally perceived with no official demarcation, and therefore no associated spatial data layers existed, we had previously used the Thiessen Polygon approach with each center point being an agreed upon heart of that community to create graduated color intensity maps (Bempah et al., 2020). We normalized each risk by the total amount of digitized locations, so each polygon displayed the amount of digitized trash as a proportion of all features (for example trash, grass overgrowth, stagnant water, etc.). There appeared to be a north east / south west split between the communities with Mobil having the highest amount of digitized trash, along with Yoomo Specs, Tebibiano, Camp 2 and Gonno School. After normalizing, Yoomo Specs and Camp 2 remained high, though ironically LEKMA, the site of the hospital, rises to the top. One point to note is that while the amount of trash in Mobil reduces in rank when normalized, the other variables being digitized (such as stagnant water, grass overgrowth, mud, etc.) still can contribute to other health risks. Indeed, the six communities mentioned, along with Bukueshie, all possess visible levels of trash and other environmental risks, such as visible standing water that should cause concern.

All videos, irrespective of location, contained some trash related description. Further investigation of these trash related themes can be seen in Figs. 6 and 7 which display word clouds created from one narrative and then all the narratives, respectively. While the dominance of "rubbish" (meaning trash), "gutter" (meaning drainage) is evident, these and related themes are contextualized by other phrases which help explain the perceived impact on the "environment", or other societally relevant outcomes such as food sources (especially fishing). While the use of Wordmapper helped identify themes, the next step was to return to the narratives for deeper contextualization (Curtis, Tyner, et al., 2019), for example how the combination of dumping and flooding contaminated local fish resources. In other words, the deeper reading of the text helped explain how each keyword was used by the subject and in what context. At the same time, key locations, such as the cemetery, could be linked to the text and contextualized in terms of its role in the trash complex (eg. a perceived location for drug use and increased mosquito activity).

Table 1 provides an overview of this frequency of terminology displaying the various synonyms used to describe the interconnected terms of trash, drain and poverty. Another way of visualizing these mentions is in a word cloud generated from all the SVGs (Fig. 7). Irrespective of visualization type, each displayed the importance of trash by those interviewed, especially in connection to health outcomes. It is worth noting again that discussing trash was not the stated intention of these interviews, but rather the malaria risk in the area.

Other connected themes were also be gleaned from the narratives regarding the causes of and implications of trash dumping. In terms of causation, there were multiple mentions of the financial hardships involved, including direct quotes related to how the local populace simply cannot afford to pay for trash removal. And in terms of consequence, the contamination of local food especially fish was described, these being contaminated by the excess trash dumped into the drainage systems which empty 
directly into the sea. The point was emphasized that people in these communities are reliant on these local food sources and hence these contaminants indirectly affect their gastro-health.

Table 1

Themes based on the key word mentions. All SVGs were collected by driving through the town unless otherwise noted. $10 \mathrm{a}$ and $10 \mathrm{~b}$ are the same participant where the route was split between walking and driving due to road inaccessibility issues. The last two columns show the frequency of mention for words related to each theme occurring in each of the transcribed sentences.

\begin{tabular}{|lllll|}
\hline $\begin{array}{l}\text { Participant } \\
\#\end{array}$ & $\begin{array}{l}\text { Video length (mm: } \\
\text { ss) }\end{array}$ & $\begin{array}{l}\text { Total number of } \\
\text { sentences }\end{array}$ & \multicolumn{2}{l|}{ Key word matches (Frequency) } \\
\cline { 3 - 5 } & & & $\begin{array}{l}\text { Trash and drainage } \\
\text { channels }\end{array}$ & Poverty \\
\hline 1 & $34: 10$ & 328 & 53 & 11 \\
\hline 2 & $27: 52$ & 183 & 33 & 6 \\
\hline 3 & $43: 14$ & 275 & 33 & 5 \\
\hline 4 & $31: 49$ & 248 & 15 & 13 \\
\hline 5 (walking) & $16: 03$ & 69 & 14 & 6 \\
\hline 7 (walking) & $13: 57$ & 130 & 7 & 3 \\
\hline 8 & $47: 50$ & 263 & 34 & 12 \\
\hline 9 & $42: 01$ & 349 & 37 & 1 \\
\hline $10 a$ & $17: 19$ & 157 & 12 & 0 \\
\hline (walking) & $3: 50$ & 23 & 12 & 13 \\
\hline $10 b$ & $30: 02$ & 233 & 36 & 8 \\
\hline 11 & $19: 33$ & 115 & 7 & \\
\hline
\end{tabular}

\subsection{Geographic Variations}

Visually, communities with relatively higher income such as Agblezaa, Malik, and Tebibiano, had cleaner environments, whereas the lower income Bukueshie, Mobil, Adoemli, Lascala, Camp 2, Yoomo Specs and Teshie NDC displayed classic signs of vulnerability (Bempah et al., 2020). While trash was still visible in the higher income neighborhoods, the overall situation was far better, including cleaner streets and concrete covered drains (Fig. 8). Of particular interest, however, was the way the trash complex was described by respondents in the different areas. While for some the illegal dumping was a product of poverty, with locals not being able to afford (or have the political voice to argue for) adequate affordable services, some of the interviewees suggested that the problems were more behavioral (and sometimes ethnic). Residents in the most impoverished communities were sometimes described as being laidback, overly reliant on welfare and too willing to rely on the government to solve the situation. In comparison, 
response from the higher income (comparatively) communities had a broader perspective and a desire to protect the local environment. An example of this varying perspective came with local community clean up events organized at a grass roots level. The following quotes capture both the positive efforts enacted regarding improving local infrastructure and measures to reduce local dumping (italicized words can be directly linked to mapped locations and associated images):

...They pay more attention to their environment than the other places.... Because they sometimes organize tractors to come and dig inside the gutter. As you can see, they were just laying some side blocks on the gutter so that I mean it will be very clean for them to I mean use."

They have put a container at where we dump rubbish, and you pay one (1) cedis before you throw your rubbish in the dumpster. But some people cannot afford to do that...So somebody is there when you bring your rubbish, the person takes money from you and pours it into the rubbish container before the car comes for it and takes it away. So, what I am thinking is that, in an environment like this when you make people pay for rubbish it doesn't work because people don't have money. Most of them will dump in the sea. They should actually make it free for them.

The video frame visuals (Fig. 8) support these comments in terms of the area being largely trash free, with litter being lose and trapped in between plant/grass overgrowth. The drains, which were mostly covered in the better income communities displayed little evidence of standing water or trash. No community dumpsites were observed as almost all households had trash containers that were regularly picked up by waste services. It is useful to refer to Fig. 5 , the distances between these such markedly different communities are not large, just a few miles.

By addition, trash was more visible in the poorer areas, especially in the drains, while burning and illegal or infrequently collected trash heaps could also be seen and were frequently described. Figure 9 shows one such illegal dumpsite, located by the ocean, and proximate to local fishing. Ironically even these illegal dumpsites are not convenient for many residents who still live too far away. Even when dumpsters were seen, these were overflowing indicative of an infrequent removal, possibly because of the local inability to pay for the service (Fig. 10).

"Yes, first initially there was Zoomlion. When they started this Zoomlion thing they were very very effective. You will not even come here and see this kind of rubbish around the place. Every time they have their tricycle, going around, collecting rubbish and stuff because it was a company.

So, I don't know what happened. The government has a deal with them and then now they are not doing what they are supposed to do. I don't know the terms of the contract they had with them, but they are not doing what they are supposed to do comparing to the initial stage where they started as Zoomlion."

When the SVG was collected close to these types of trash accumulations the commentary frequently mentioned the associated smell.

"The smell is quite bad. We have the cemetery here and the place is so messy. 
How do they breathe, like the whole place smells really bad?

Look at this big gutter here. All the stagnant waters from up there, comes here. As the gutter is choked you can smell the odor around. Very, very bad. It is always dirty. It's always dirty. Even if someone should build by the roadside, the person would direct the water into the gutter. So the same gutter flow everywhere. So you cannot smell any good scent in the community. Always dirty. Not easy oo. This place smells bad."

\subsection{The Role of Drains}

Many of the narratives described the interconnection between the drainage system and the local trash complex. While the purpose of the drains is to carry away wastewater and excess water during rain events, these also too frequently present a free option for solid waste dumping. Indeed, the local perception gleaned from the narratives is that when the drains were in full flow the strength of the water would be an effective transport mechanism and carry the material away. Therefore, with more rain would come more dumping. However, the logic is flawed as some objects are too large to be moved over long distances even during heavy rains, and this efficiency decreases as the water flow reduces either through a drop-in rainfall or by channel clogging, leading to problems "down" channel. As a result, sections of the drain would have stagnant water pools trapped by the dumped objects (leading to mosquito breeding) and a putrid smell which was frequently commented on in the SVGs. Some interviewees also commented that those dumping their trash did not know or care about the implications of these actions as the consequence would tend to be further down channel, in other words these were another community's problems. The clogging effect not only had a damming effect to hinder the transport of the waste material, but it could also lead to water overspilling the drain banks. This situation was particularly problematic during heavy rains and, as the drain got closer to the coast, the inflow of tides:

Our major problem is the gutter. When it rains, you can even go have a look at it. No matter the season, people dump all kinds of trash into the gutter. When the ocean overflows, it pushes all the trash and water here through the gutter. The gutter can get so full that it overflows into our homes with the rubbish in it. Right from the top over there. When the ocean overflows, then it pushes the rubbish this way through the gutter. It sometimes gets into our rooms along with all the rubbish. Whilst the gutter is overflowing and then you see someone pouring rubbish into it. And then, this eventually gets into our homes. When the gutter starts getting full of water, then it starts to flood this place.

It is worth noting again that the italicized section above illustrates the benefit of the SVG, where not only are the actions described but these can be visually identified and investigated, while also being spatially tagged for mapping.

The consequence of the dumping-and-clogging effect was that even during the dry season water would remain in the channel, and newly added wastewater would pool because of the detritus. This had the effect of extending mosquito breeding and increased malaria risk: 
Even in the absence of rain, the gutter is always filled with trash. The trash sometimes piles up so much and starts getting rotten. And this eventually leads to the breeding of a lot of mosquitoes. So, the area always smells bad, and the mosquitoes and diseases are all year round.

\subsection{Organic and Inorganic Matter}

Almost any item imaginable was either seen in the videos or described in the SVGs, including inorganic and various organic matter. The narratives also suggested chemicals and other toxins would also be dumped. One of the most frequently described, and visibly identifiable discarded categories was plastic. These can easily be seen in previous images, for example Figs. 9 and 10, and in the drains feeding into the coastal areas. The resulting deposits along the coastline pose both a problem to local ecosystems (Bouwmeester et al., 2015), as well as providing containers for mosquito breeding. While many African countries have enacted bans on the use of plastics (Adam et al., 2020; Nyathi \& Togo, 2020), Ghana is yet to join in this due to the large number of plastic industries present in the country and tax exemptions on plastics (Mensah, 2020) which has contributed greatly to the increased use of plastics and the individual resistance towards proper waste disposal. It is therefore not surprising to see so many examples given this ongoing laissez faire attitude (Richard et al., 2020).

Mixed in with the plastics are byproduct of organic waste from vendors and the home, and more worryingly sanitary waste including plastic bags containing human excreta, used diapers, and as seen in some of the videos, people practicing open defecation in the drains. One participant who was a community nurse in the town, recounted while also pointing out someone defecating:

The biggest headache is the gutter. People throw rubbish and some go to toilet in the gutters. As you can see, people are defecating in the gutters. And they also throw rubbish in there. So, it breeds a lot of mosquitoes which disturbs us a lot.

As has frequently described in the literature, one particularly vulnerable cohort are children who are the closest to many of these environmental problems. This problem is further supported in the video where children can be seen in or around the drains, either using discarded items as play toys (Fig. 11), or the channels as play environments. Similar visuals linking children's play spaces to hazardous environments has been previously described in other spatial video supported projects (Curtis, Squires, et al., 2019).

Finally, as previously mentioned, a further broader impact to multiple communities was the way trash could contaminate the local food supply. More specifically, items would be ingested by fish in ocean. Sometimes this contamination was visible with objects being caught in the fish's mouth, though a local concern was the uncertainty of how tainted was the meat. As lamented by an interviewee:

...Because of the trash at the shore, it affects the sea creatures. Sometimes you buy fish, and there is trash in its mouth. I'm referring to smoked fish not the fresh fish. I think maybe because some of the fish's mouth are closed. Most of the diseases too I think are from the fish. Because they eat all kinds of filth that go into the sea. So, we will definitely get sick. We get sick from all angles: the gutter, the fishes and the sea... 


\subsection{Discussion}

Teshie, a coastal town connected to Accra in Ghana is typical of many impoverished areas where poor sanitation practices (Berendes et al., 2018, 2020) affect the local quality of life, and contribute to various local health problems. The lack of any effective waste disposal, along with poverty related attitudes and actions, presents a complex problem (Oteng-Ababio, 2011). While research has often focused on this problem in general terms, (Cobbinah, Addaney, \& Agyeman, 2017; Oteng-Ababio, 2011; Yirenya-tawiah, Nii, Kotei, Annang, \& Yirenya-tawiah, 2020), there has generally been a lack of contextualized geographic data that can help explain the heterogeneity of the problem at a granular geographic scale, along with perceived causations and solutions. Acquiring this level of granular insight is vital in terms of how it can then inform effective intervention (Okami \& Kohtake, 2017). In this paper we use a spatial video geonarrative to leverage three different but connected data streams that can be used to not only locate problems (and then map then), but also understand their importance through expert or local commentary, with supporting visuals.

Figure 12 provides an overview of the Teshie Trash Complex as pieced together from the spatial video and narratives. Three example neighborhoods are shown, as well as the links between each.

Neighborhood A, which is low income, has no official trash removal services. As a result, residents tend to dump illegally, either in the drains, or on places with little oversight, or they dispose using methods such as burning. Each of these presents potential negative health consequences, from the breeding potential of discarded plastic containers to organic matter (including feces) causing enteric disease outbreaks. With a particular proximity focus on the latter are homes close to dump sites, or food vendors who locate close to the drain leading to contamination through water or flies. At greatest risk are children who play in and around (and sometimes within) the dumped material. Finally, burning of trash could also lead to particulate matter or chemical exposure for those living nearby or downwind.

Temporal variation occurs with more dumping occurring during the rains (due to the perception of drain water being able to wash away larger items). While localized flooding may occur, the general perception is that the risks caused by dumping are faced by others away from the community. However, as these actions are because of severe poverty, there is little concern over these displaced consequences.

Neighborhood B, unlike A, is middle income, and therefore has regular trash disposal paid for by residents. In addition, local infrastructure is both better and well maintained, the most obvious example being covered drains. As a result, many of the health risks in Neighborhood A will not occur around the drains because there will be less mosquito breeding, less clogging and flooding, with less food contamination (for example) from flies moving from human waste to vendors food. As a result, food vendors, community children, and residences close to drains are all relatively safer. In addition, there is social capital within the community to deal with any emergent problems - for example if a trash problem did occur, it is more likely the residents would band together to find a solution. There is, however, a potential spillover effect if Neighborhood A borders Neighborhood B based on mosquito flight range (Ejerctto \& Urbino, 1951), and, though less likely, if any of the drainage from A is connected to $B$. 
Neighborhood $\mathrm{C}$ has a similar situation to $\mathrm{A}$. The same economic pressures lead to a trash problem. However, the situation is arguably worsened because of two factors. Firstly, this community is down drain of Neighborhood A, meaning that trash dumped there flows into B, may clog the channel, and cause localized flooding into the homes. In addition to this flood risk, there will be more containers for mosquito breeding, and arguably more fecal content (increasing the risk of enteric disease). The mosquito risk will extend into the dry season because of water pooling in the discarded containers, or because of localized clogs. Geographic risk will be greater around the drain, and where trash and mud accumulate due to flooding. While food vendors and children will again be at risk, arguably these risks will be even more elevated than for $\mathrm{A}$. The second contributing factor is that $\mathrm{C}$ is also closer to the coast, meaning that incoming tides are more likely to prevent downflow, increasing the chance of trash clogging and flooding. In other words, even though the situations of $\mathrm{A}$ and $\mathrm{C}$ are similar, the site of $\mathrm{C}$ leads to even greater disparity.

Finally, arguably the environment that suffers most from trash being dumped anywhere in the drainage system is the coast. The estuary and beaches are thick with trash posing multiple health problems for those who reside there, especially children. The scale of the deposits exceeds any local solution and would need governmental assistance to be removed. The smell is intense and the water in both the drain and the surrounding sea is likely to be heavily polluted (Curtis, Squires, et al., 2019); making the area extremely unpleasant for local residents. Finally, and with implications for Neighborhoods A, B and C, fish stocks are contaminated with the potential to cause sickness.

While Fig. 12 provides a summary of the overall cycle, it should be remembered that the SVG underlying this provides local detail in the form of maps, images and context that can also be used to understand the specific problem (why it exists and where) but also possible solutions. For example, the map in Fig. 11 could be used to target specific interventions.

What is evident is that, unlike as stated in some of the narratives, this is not just a local problem caused by local behavioral situations. While there are general initiatives aimed at the repurposing of plastic waste (Agyeman et al., 2019; Appiah et al., 2017; Debrah et al., 2021), the overall lack of a Ghanaian governmental desire to control the use of plastics limits the effectiveness of any local initiative.

There is also limited scope in thinking education will lead to a change in behavior. As suggested by some, it is unrealistic to believe that lower income communities will organize periodic clean up exercises as developed in some of their higher income neighbors, partly because of the complex struggles associated with poverty, and partly because of the perception the impact is felt elsewhere. Simply put, for those struggling financially, more emphasis is on daily survival and expending time and energy on environmental cleanup is seen as a luxury. This situation is compounded by there also being fewer official trash removal services in these areas, again because of the inability of residents to pay for those services.

Yet what is clear in the SVGs, and can be seen in Fig. 12, is that the problems extend beyond any one neighborhood and require broader thinking and intervention. Guaranteeing funding for regular trash 
removal will reduce the need for dumping, leading to a cleaner environment, less sickness, and fewer lost labor days. It is also imperative to just think about these problems daily as the damage caused, especially the coastal areas, requires considerable attention far exceeding any local neighborhood ability.

While expecting such government intervention to cover drains, improve local waste collection sites and schedule regular (free) pickups, and implement considerable environmental cleanup operations is probably unrealistic, the SVGs also hint at more local options that lead to smaller incremental improvements. One such strategy as we have described previously is sand "winning" from the gutters for local construction (Bempah et al., 2020). With more and temporally updated SVG collection it is entirely possible that other such local strategies can be identified, evaluated, and then scaled up as a multi neighborhood strategy.

\subsection{Conclusion}

The local trash situation in Teshie poses a complex problem, with various infectious disease implications including malaria (Amoatey et al., 2008), cholera (Addo et al., 2017), leishmaniasis (Ivović et al., 2015), and other vector borne diseases (M.T et al., 2019; Sheela et al., 2017). What is needed is a way to collect contextualized spatial data that can both reveal those local risks, while also revealing the connective issues between multiple environments. Understanding this complex means there is better chance of understanding how to improve the local situation. Otherwise, interventions, and costs, will be focused heavily on poor health outcomes rather than addressing the contributing factors. This paper has shown how SVGs can be used as a localized targeting tool to understand within-neighborhood risk while also providing the context required to understand the "bigger picture". Finally, the use of SVG in the Teshie environment has shown the universality of these problems in similar environments for countries such as Haiti and Kenya. Therefore, while this is a local tool designed to support local intervention, insights revealed are translational and can be used to develop a more spatially informed theory regarding the trash-health complex in the most challenging environments.

\section{Declarations}

\section{Acknowledgments}

We are grateful to Kent State University and Case Western University for granting us the funds that was needed to conduct this work. Our heartfelt gratitude also goes to Infectious Disease Research Lab of the West African Center for Cell Biology of Infectious Pathogens, Department of Biochemistry, Cell and Molecular Biology, University of Ghana, Legon, Ghana, for the support in providing the personnel needed to conduct on-the-ground data collection.

\section{Funding}

This research was funded by the Kent State Healthy Communities Research Initiative Mapping to Support Health Interventions in the World's Most Challenging Environments 2018-2019, the Graduate Student 
Senate of Kent State University, and the Department of Population and Quantitative Health Sciences, Case Western Reserve University School of Medicine.

\section{Author contributions}

Conceptualization: A.C. and S.B.; Data curation: S.B., N.N; Formal analysis: S.B.; Funding acquisition: S.B., A.C.; Investigation: S.B., A.C.; Methodology: A.C., S.B., and J.A.; Project administration: A.C., G.A.; Resources: A.C., G.A.; Supervision: S.B.; Software: J.A.; Validation: A.C.; Visualization: S.B.; Writingoriginal draft: S.B.; Writing-review \& editing: A.C, S.B.

\section{Declaration of Interest}

Authors declare no conflict of interest. Funders had no influence in the design of this research, data acquisition, interpretation of data nor the publishing of these results.

\section{Ethical Approval}

Ethical approval was provided by Kent State University Institutional Review Board.

\section{Availability of data and materials}

The datasets used and/or analysed during the current study are available from the corresponding author on reasonable request.

\section{Ethics approval and consent to participate}

Not applicable

\section{Consent for publication}

Not applicable

\section{References}

1. Adam I, Walker TR, Bezerra JC, Clayton A. (2020). Policies to reduce single-use plastic marine pollution in West Africa. Marine Policy, 116(June 2019), 103928. https://doi.org/10.1016/j.marpol.2020.103928.

2. Addai KN, Danso-Abbeam G. Determinants of willingness to pay for improved solid waste management in Dunkwa-on-Offin, Ghana. Journal of Agriculture Environmental Sciences. 2014;3(1):1-9.

3. Addo HO, Dun-Dery EJ, Afoakwa E, Elizabeth A, Ellen A, Rebecca M. Correlates of domestic waste management and related health outcomes in Sunyani, Ghana: A protocol towards enhancing policy. BMC Public Health. 2017;17(1):1-10. https://doi.org/10.1186/s12889-017-4537-8. 
4. Agyeman S, Obeng-Ahenkora NK, Assiamah S, Twumasi G. Exploiting recycled plastic waste as an alternative binder for paving blocks production. Case Studies in Construction Materials. 2019;11:e00246. https://doi.org/10.1016/j.cscm.2019.e00246.

5. Ahmed MT, Loutfy NM, Osman MAM, Godfrey L. (2018). Impacts of waste in Africa. Africa Waste Management Outlook, 71-98.

6. Ajayakumar J, Curtis A, Smith S, Curtis J. (2019). The Use of Geonarratives to Add Context to Fine Scale Geospatial Research. International Journal of Environmental Research Public Health, 16(3). https://doi.org/10.3390/ijerph16030515.

7. Amoah A. (2018). Willingness to Pay for Improved Solid Waste Collection and Its Implication on Business Orientation Practices of Local Governments in Ghana. 6(3), 77-97. https://doi.org/10.12691/env-6-3-4.

8. Amoatey P, Winter J, Kaempf C. (2008). Solid Waste Disposal and the Incidences of Malaria: Any Correlation? Proceedings of the Second, September 2008. http://www.actapress.com/PDFViewer.aspx? paperld=34124.

9. Appiah JK, Berko-Boateng VN, Tagbor TA. Use of waste plastic materials for road construction in Ghana. Case Studies in Construction Materials. 2017;6:1-7. https://doi.org/10.1016/j.cscm.2016.11.001.

10. Asase M, Yanful EK, Mensah M, Stanford J, Amponsah S. Comparison of municipal solid waste management systems in Canada and Ghana: A case study of the cities of London, Ontario, and Kumasi, Ghana. Waste Manag. 2009;29(10):2779-86. https://doi.org/10.1016/j.wasman.2009.06.019.

11. Ashbolt NJ. Microbial contamination of drinking water and disease outcomes in developing regions. Toxicology. 2004;198(1-3):229-38. https://doi.org/10.1016/j.tox.2004.01.030.

12. Bempah S, Curtis A, Awandare G, Ajayakumar J. Appreciating the complexity of localized malaria risk in Ghana: Spatial data challenges and solutions. Health Place. 2020;64:102382. https://doi.org/https://doi.org/10.1016/j.healthplace.2020.102382.

13. Bempah S, Odhiambo L, Curtis A, Pandit A, Mofleh D, Ajayakumar J, Odhiambo LA. Fine scale replicable risk mapping in an informal settlement: A case study of mathare, nairobi. J Health Care Poor Underserved. 2021;32(1):354-72. https://doi.org/10.1353/hpu.2021.0028.

14. Berendes DM, de Mondesert L, Kirby AE, Yakubu H, Adomako, Lady, Michiel J, Raj S, Robb K, Wang Y, Doe B, Ampofo J, Moe CL. (2020). Variation in E. coli concentrations in open drains across neighborhoods in Accra, Ghana: The influence of onsite sanitation coverage and interconnectedness of urban environments. International Journal of Hygiene and Environmental Health, 224(December 2019), 113433. https://doi.org/10.1016/j.jheh.2019.113433.

15. Berendes DM, Kirby AE, Clennon JA, Agbemabiese C, Ampofo JA, Armah GE, Baker KK, Liu P, Reese $\mathrm{HE}$, Robb KA, Wellington N, Yakubu H, Moe CL. Urban sanitation coverage and environmental fecal contamination: Links between the household and public environments of Accra, Ghana. PLoS ONE. 2018;13(7):1-19. https://doi.org/10.1371/journal.pone.0199304. 
16. Boadi KO, Kuitunen M. Urban waste pollution in the Korle Lagoon, Accra, Ghana. Environmentalist. 2002;22(4):301-9. https://doi.org/10.1023/A:1020706728569.

17. Bouwmeester $\mathrm{H}, \mathrm{Hollman} \mathrm{PCH}$, Peters RJB. Potential Health Impact of Environmentally Released Micro- and Nanoplastics in the Human Food Production Chain: Experiences from Nanotoxicology. Environ Sci Technol. 2015;49(15):8932-47. https://doi.org/10.1021/acs.est.5b01090.

18. Bukari FIM, Doke DA, Kendie SB, Anokye NA. Examination of Household Solid Waste Management in Nadowli Township in Ghana: A Waste Management Hierarchy Approach. Ghana Journal of Development Studies. 2017;14(2):184. https://doi.org/10.4314/gjds.v14i2.10.

19. Cobbinah PB, Addaney M, Agyeman KO. Locating the role of urbanites in solid waste management in Ghana. Environmental Development. 2017;24:9-21. https://doi.org/10.1016/j.envdev.2017.06.004.

20. Curtis A, Bempah S, Ajayakumar J, Mofleh D, Odhiambo L. Spatial Video Health Risk Mapping in Informal Settlements: Correcting GPS Error. International Journal of Environmental Research Public Health. 2018. https://doi.org/10.3390/ijerph16010033.

21. Curtis A, Blackburn JK, Widmer JM, Morris JG. A ubiquitous method for street scale spatial data collection and analysis in challenging urban environments: mapping health risks using spatial video in Haiti. International Journal of Health Geographics. 2013;12(1):21. https://doi.org/10.1186/1476072X-12-21.

22. Curtis A, Curtis JW, Ajayakumar J, Jefferis E, Mitchell S. Same space-different perspectives: comparative analysis of geographic context through sketch maps and spatial video geonarratives. Int J Geogr Inf Sci. 2019a;33(6):1224-50. https://doi.org/10.1080/13658816.2018.1514609.

23. Curtis A, Curtis JW, Ajayakumar J, Jefferis E, Mitchell S. Same space-different perspectives: comparative analysis of geographic context through sketch maps and spatial video geonarratives. Int J Geogr Inf Sci. 2019b;33(6):1224-50. https://doi.org/10.1080/13658816.2018.1514609.

24. Curtis A, Curtis JW, Shook E, Smith S, Jefferis E, Porter L, Schuch L, Felix C, Kerndt PR. Spatial video geonarratives and health: case studies in post-disaster recovery, crime, mosquito control and tuberculosis in the homeless. International Journal of Health Geographics. 2015;14:22. https://doi.org/10.1186/s12942-015-0014-8.

25. Curtis A, Squires R, Rouzier V, Pape JW, Ajayakumar J, Bempah S, Alam MT, Alam MM, Rashid MH, Ali A, Morris JG. (2019). Micro-space complexity and context in the space-time variation in enteric disease risk for three informal settlements of port au prince, haiti. International Journal of Environmental Research Public Health, 16(5). https://doi.org/10.3390/ijerph16050807.

26. Curtis A, Tyner J, Ajayakumar J, Kimsroy S, Ly K, Curtis A, Tyner J, Ajayakumar J, Kimsroy S, Curtis A, Tyner J, Ajayakumar J, Kimsroy S, Ly K. Adding Spatial Context to the April 17, 1975 Evacuation of Phnom Penh : How Spatial Video Geonarratives Can Geographically Enrich Genocide Testimony Adding Spatial Context to the April 17, 1975 Evacuation of Phnom Penh : How Spatial Video Geonarratives. GeoHumanities. 2019;5(2):386-404. https://doi.org/10.1080/2373566X.2019.1624186. 
27. Debrah JK, Vidal DG, Dinis MAP. Innovative Use of Plastic for a Clean and Sustainable Environmental Management: Learning Cases from Ghana, Africa. Urban Science. 2021;5(1):12. https://doi.org/10.3390/urbansci5010012.

28. Dongzagla A, Jewitt S, O'Hara S. Seasonality in faecal contamination of drinking water sources in the Jirapa and Kassena-Nankana Municipalities of Ghana. Sci Total Environ. 2020;752:141846. https://doi.org/10.1016/j.scitotenv.2020.141846.

29. EJERCTTO A, URBINO CM. Flight range of gravid and newly emerged Anopheles. Bull World Health Organ. 1951;3(4):663-71.

30. Focks DA, Brenner RJ, Chadee DD, Trosper JH. The use of spatial analysis in the control and risk assessment of vector-borne diseases. Am Entomol. 1999;45(3):173-83. https://doi.org/10.1093/ae/45.3.173.

31. Giusti L. A review of waste management practices and their impact on human health. Waste Manag. 2009;29(8):2227-39. https://doi.org/10.1016/j.wasman.2009.03.028.

32. Ivović V, Kalan K, Zupan S, Bužan E. Illegal waste sites as a potential micro foci of Mediterranean Leishmaniasis: First records of phlebotomine sand flies (Diptera: Psychodidae) from Slovenia. Acta Veterinaria. 2015;65(3):348-57. https://doi.org/10.1515/acve-2015-0029.

33. Karley NK. (2009). FLOODING AND PHYSICAL PLANNING IN URBAN AREAS IN WEST AFRICA: SITUATIONAL ANALYSIS OF ACCRA, GHANA. Theoretical and Empirical Researches in Urban Management.

34. Kiddy-Kodua JO, Norman ID, Norvivor FA. Solid Waste Management in the Hohoe Municipality, Ghana. J Public Health Dev Ctries. 2018;4(1):450-7. http://www.jphdc.org/.

35. Krystosik A, Njoroge G, Odhiambo L, Forsyth JE, Mutuku F, LaBeaud AD. Solid Wastes Provide Breeding Sites, Burrows, and Food for Biological Disease Vectors, and Urban Zoonotic Reservoirs: A Call to Action for Solutions-Based Research. Frontiers in Public Health. 2020;7(January):1-17. https://doi.org/10.3389/fpubh.2019.00405.

36. Krystosik AR, Curtis A, Buritica P, Ajayakumar J, Squires R, Dávalos D, Pacheco R, Bhatta MP, James MA. Community context and sub-neighborhood scale detail to explain dengue, chikungunya and Zika patterns in Cali, Colombia. PLoS ONE. 2017;12(8):1-26.

https://doi.org/10.1371/journal.pone.0181208.

37. Hassan MT,NF, Farhan NA R, M., M.A, E., \& Rus R. Solid Waste: Its Implication for Health and Risk of Vector Borne Diseases. Journal of Wastes Biomass Management. 2019;1(2):14-7. https://doi.org/10.26480/jwbm.02.2019.14.17.

38. Matheson T. (2019). Disposal is Not Free: Fiscal Instruments to Internalize the Environmental Costs of Solid Waste. IMF Working Paper. https://www.imf.org/ /media/Files/Publications/WP/2019/wpiea2019283-print-pdf.ashx.

39. Mensah ACE. Tax elasticity of demand for plastic: the cause of plastic pollution in Ghana. Journal of Environmental Economics Policy. 2020;10(1):28-42. https://doi.org/10.1080/21606544.2020.1765882. 
40. Messina JP, Taylor SM, Meshnick SR, Linke AM, Tshefu AK, Atua B, Mwandagalirwa K, Emch M. Population, behavioural and environmental drivers of malaria prevalence in the Democratic Republic of Congo. Malaria Journal. 2011;10(1):161. https://doi.org/10.1186/1475-2875-10-161.

41. Muñoz-Zanzi C, Mason MR, Encina C, Astroza A, Romero A. Leptospira contamination in household and environmental water in rural communities in southern Chile. International Journal of Environmental Research Public Health. 2014;11(7):6666-80. https://doi.org/10.3390/ijerph110706666.

42. Nyathi B, Togo CA. (2020). Overview of legal and policy framework approaches for plastic bag waste management in African countries. Journal of Environmental and Public Health, 2020. https://doi.org/10.1155/2020/8892773.

43. Okami S, Kohtake N. Spatiotemporal modeling for fine-scale maps of regional Malaria endemicity and its implications for transitional complexities in a routine surveillance network in Western Cambodia. Frontiers in Public Health. 2017;5(September):1-14. https://doi.org/10.3389/fpubh.2017.00262.

44. Oteng-Ababio M. Missing links in solid waste management in the Greater Accra Metropolitan Area in Ghana. GeoJournal. 2011;76(5):551-60. https://doi.org/10.1007/s10708-010-9363-9.

45. Prüss-Ustün A, Wolf J, Bartram J, Clasen T, Cumming O, Freeman MC, Gordon B, Hunter PR, Medlicott K, Johnston R. (2019). Burden of disease from inadequate water, sanitation and hygiene for selected adverse health outcomes: An updated analysis with a focus on low- and middle-income countries. Int J Hyg Environ Health, 222(5). https://doi.org/10.1016/j.ijheh.2019.05.004.

46. Qasim M, Xiao H, He K, Noman A, Liu F, Chen MY, Hussain D, Jamal ZA, Li F. Impact of landfill garbage on insect ecology and human health. Acta Trop. 2020;211(June):105630. https://doi.org/10.1016/j.actatropica.2020.105630.

47. Raju AK. Community Mobilization in Aedes aegyfti Control Programme by Source Reduction in PeriUrban District of Lautoka, Viti Levu, Fiji Islands. Dengue Bulletin. 2003;27:149-55.

48. Richard A-A, Richard N, Ahwireng AK. Integrated Waste Management System as a Sustainable Option for Managing Plastic Waste in Ghana: The Case of Madina-La Nkantanan Municipality. Journal of Scientific Research Reports. 2020;26(9):20-31. https://doi.org/10.9734/jsrr/2020/v26i930306.

49. Safo-adu G, Wara EN, Azure JA. (2019). Status of Sanitation and Hygienic Conditions in Urban Communities in Gomoa East District, Ghana. 5(2), 130-137.

50. Sheela AM, Ghermandi A, Vineetha P, Sheeja RV, Justus J, Ajayakrishna K. Assessment of relation of land use characteristics with vector-borne diseases in tropical areas. Land Use Policy. 2017;63:36980. https://doi.org/10.1016/j.landusepol.2017.01.047.

51. Singh A. (2019). Remote sensing and GIS applications for municipal waste management. Journal of Environmental Management, 243(December 2018), 22-29.

https://doi.org/10.1016/j.jenvman.2019.05.017.

52. Studies G. (2018). Genocide Studies and Prevention: An International Journal. 12(3). 
53. Tadesse T, Ruijs A, Hagos F. Household waste disposal in Mekelle city, Northern Ethiopia. Waste Manag. 2008;28(10):2003-12. https://doi.org/10.1016/j.wasman.2007.08.015.

54. Teunis PFM, Reese HE, Null C, Yakubu H, Moe CL. Quantifying contact with the environment: Behaviors of young children in Accra, Ghana. Am J Trop Med Hyg. 2016;94(4):920-31. https://doi.org/10.4269/ajtmh.15-0417.

55. Townes LR, Mwandama D, Mathanga DP, Wilson ML. Elevated dry-season malaria prevalence associated with fine-scale spatial patterns of environmental risk: a case-control study of children in rural Malawi. Malaria Journal. 2013;12(1):407. https://doi.org/10.1186/1475-2875-12-407.

56. Triassi M, Alfano R, Illario M, Nardone A, Caporale O, Montuori P. Environmental pollution from illegal waste disposal and health effects: A review on the "triangle of death. International Journal of Environmental Research Public Health. 2015;12(2):1216-36. https://doi.org/10.3390/ijerph120201216.

57. Verutes GM, Fiocco MB, Weeks JR, Coulter LL. Health, Poverty, and Place in Accra, Ghana: Mapping Neighborhoods. Journal of Maps. 2012;8(4):369-73. https://doi.org/10.1080/17445647.2012.744365.

58. Wang F, Cheng Z, Reisner A, Liu Y. Compliance with household solid waste management in rural villages in developing countries. J Clean Prod. 2018;202:293-8. https://doi.org/10.1016/j.jclepro.2018.08.135.

59. Yirenya-tawiah D, Nii P, Kotei K, Annang TY, Yirenya-tawiah D. (n.d.). Stakeholder Participation for Sustainable Solid Waste Management in Ga West Municipality, Stakeholder Participation for Sustainable Solid Waste Management in Ga West Municipality, Accra - Ghana.

60. Yoada RM, Chirawurah D, Adongo PB. Domestic waste disposal practice and perceptions of private sector waste management in urban Accra. BMC Public Health. 2014;14(1):1-11. https://doi.org/10.1186/1471-2458-14-697.

\section{Figures}




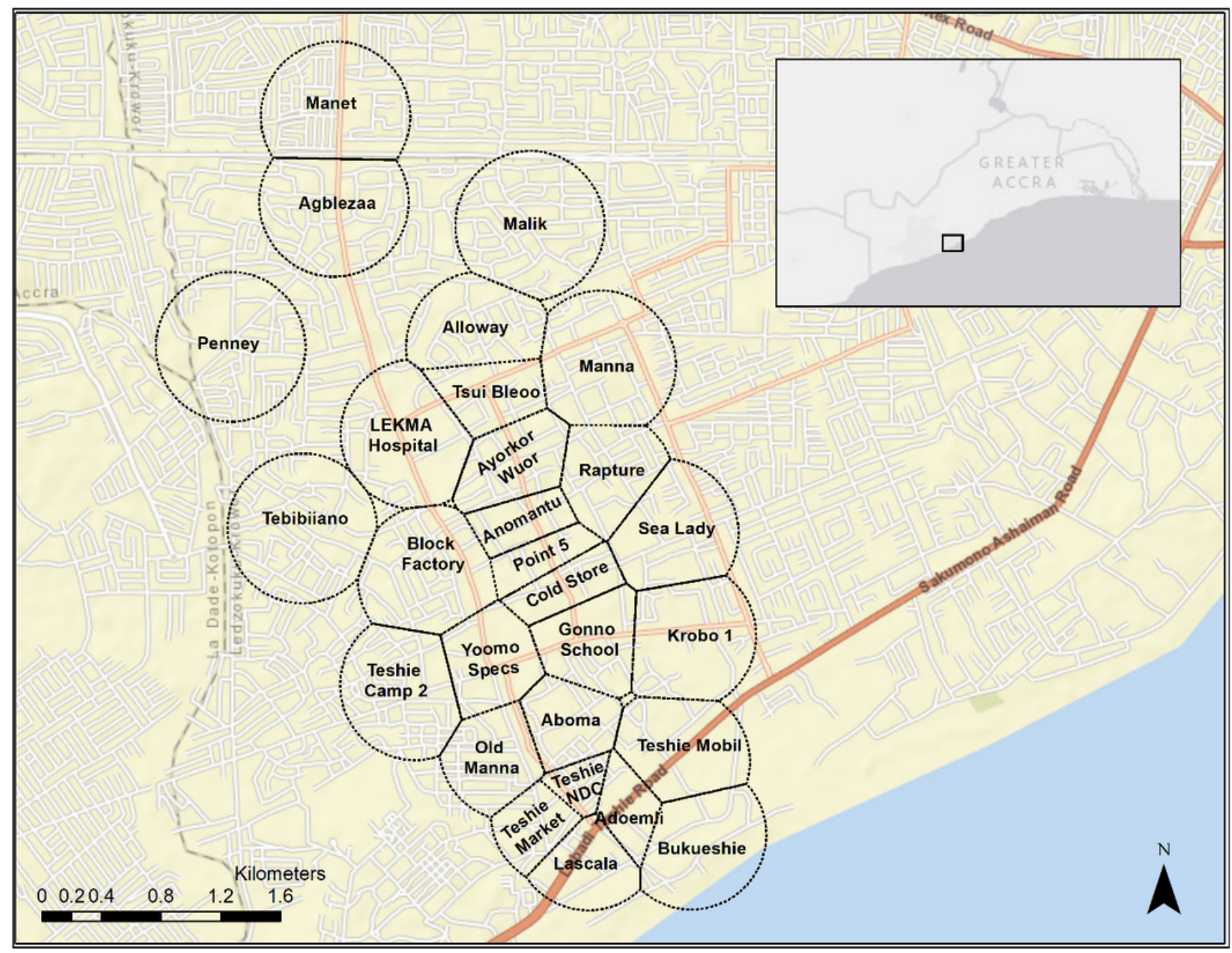

Figure 1

The communities within Teshie where this study was carried out. Due to a lack of established community boundaries, separation between neighborhoods was created using the thiessen polygon feature in ArcGIS (Bempah et al., 2020) 


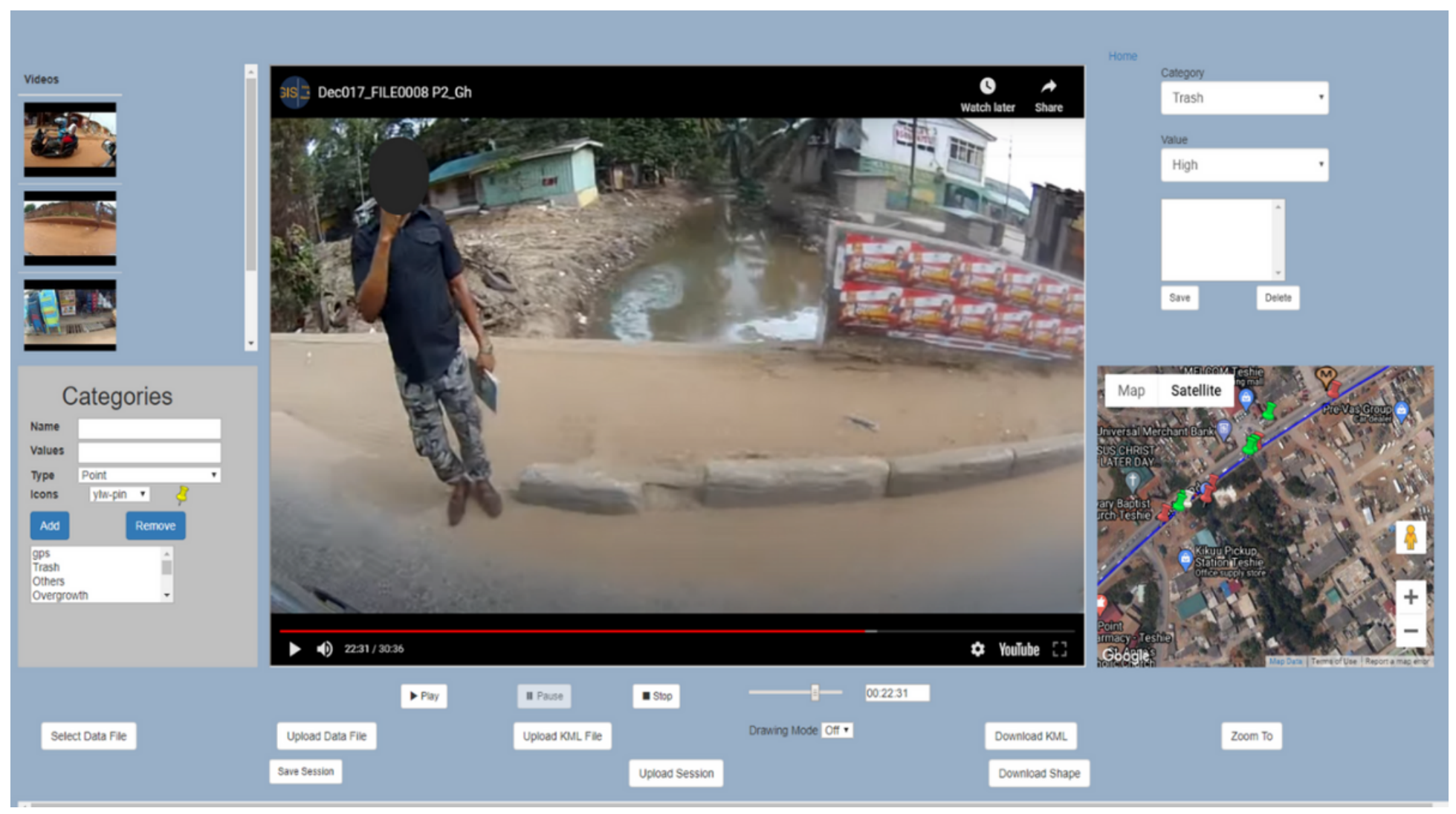

Figure 2

Video player. Software used to digitize (map out) risk features such as trash, stagnant water, and trash dumpsites seen in the video. The inset map corresponds to the map area shown in Figure 3. The image shows a typical drainage channel with trash, especially plastic containers. 


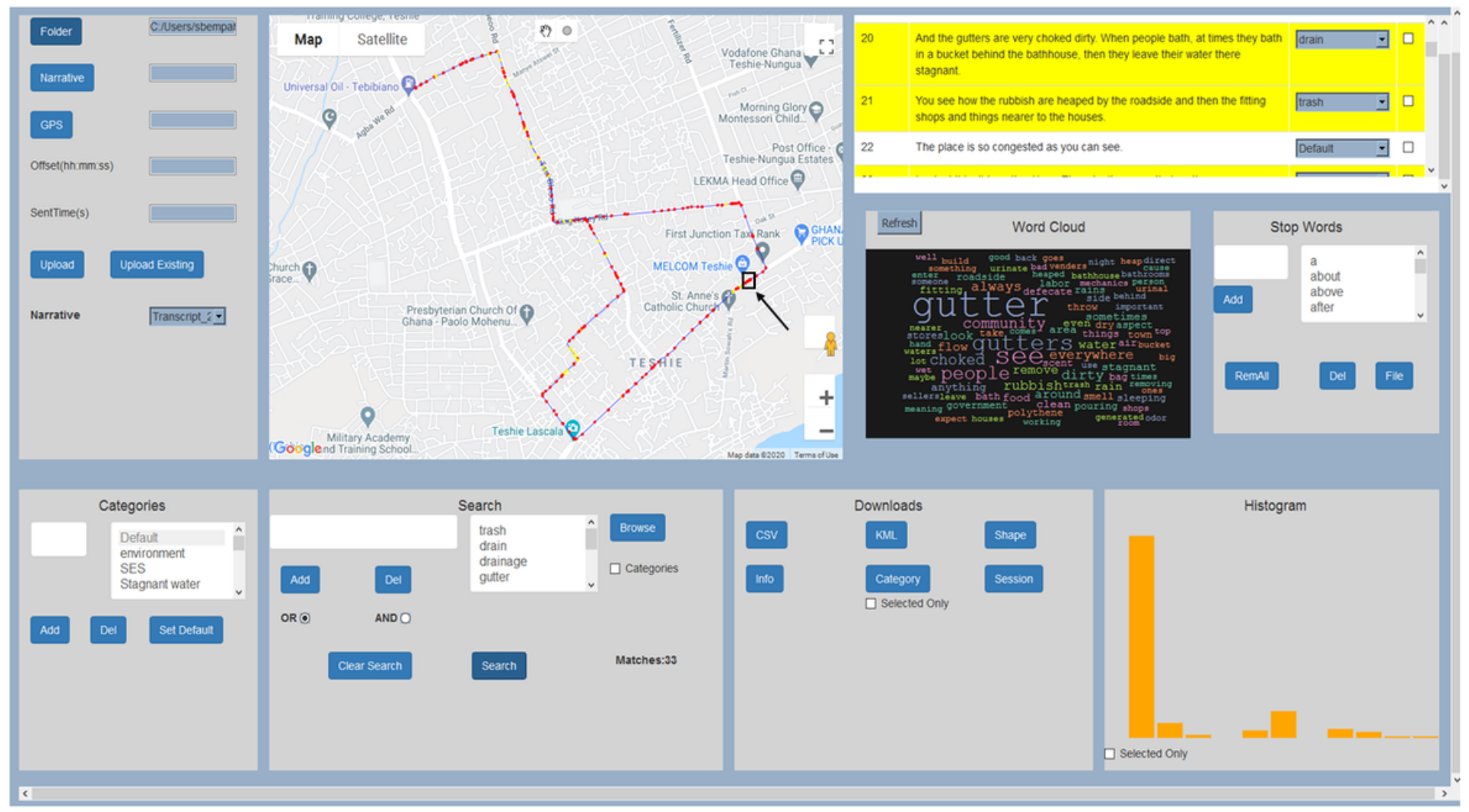

\section{Figure 3}

Wordmapper: The window with the map displays the path taken during the interview and each place marker represent a statement that was made at that location. Each sentence is displayed in the top right window. The highlighted text are keyword search results whose location are also displayed on the map window as yellow points. The area in the box is shown in detail in Figure 2. 


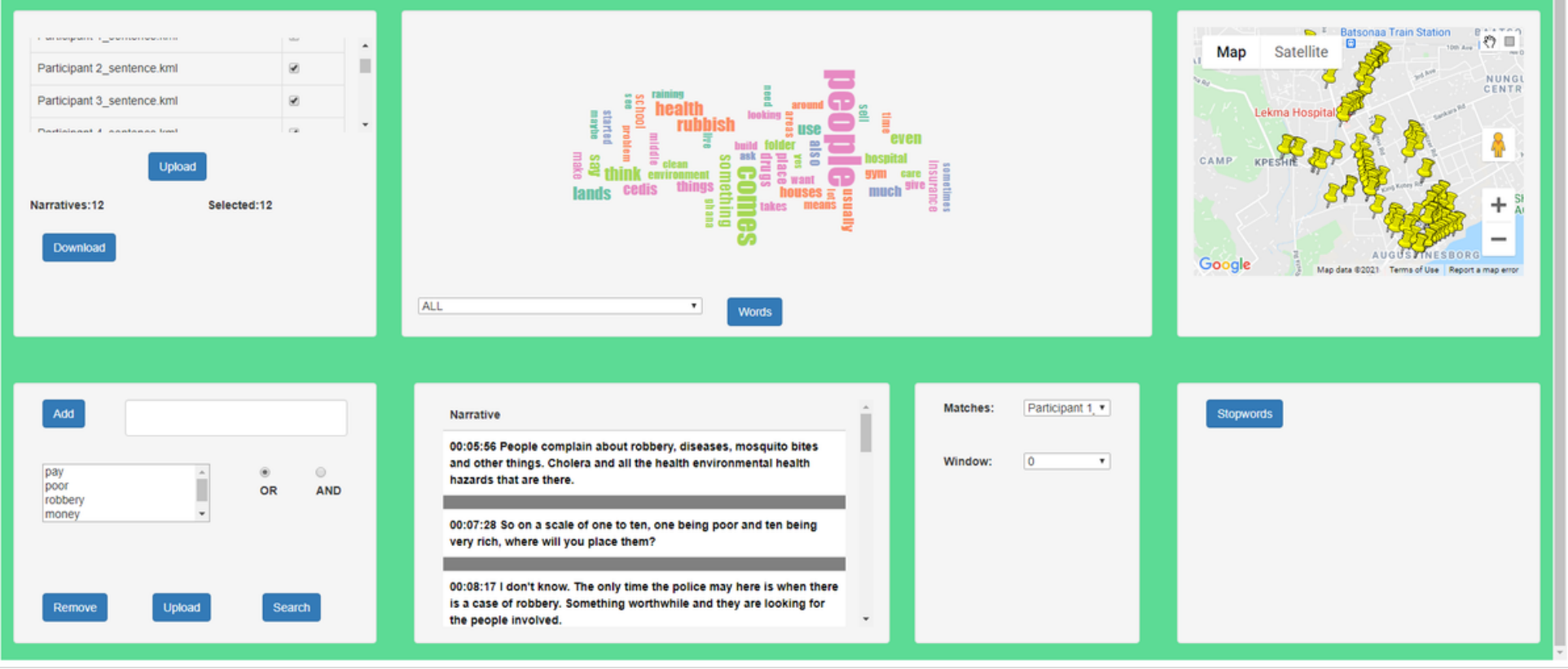

\section{Figure 4}

Geonarrative search software interface. The place markers in the map window on the top right display the spatial location of specific mentions of the search words. 

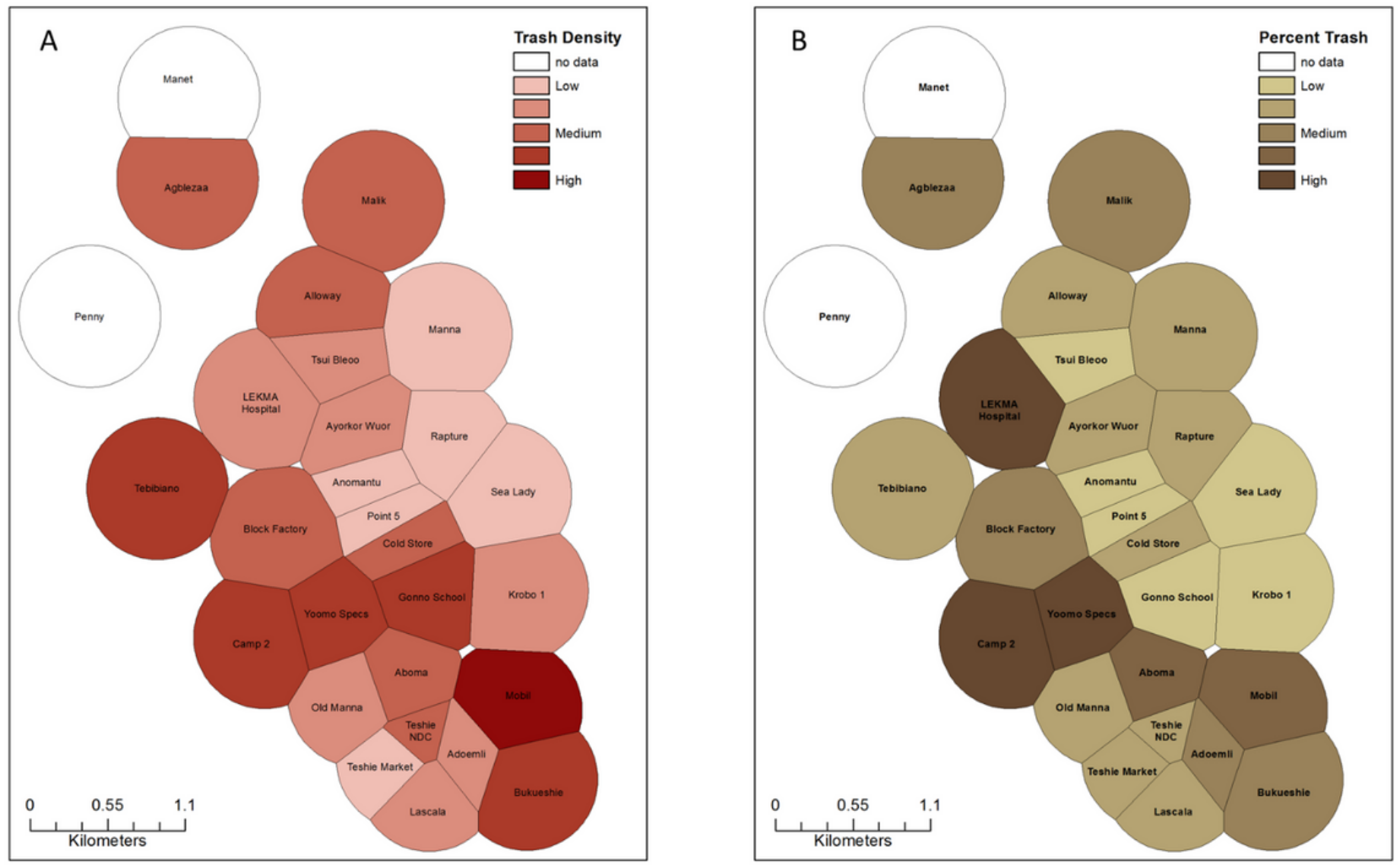

\section{Figure 5}

Distribution of trash in the communities where SVGs were collected. Community boundaries were created using the Thiessen polygon feature and clipped within a 50km buffer. A) Trash expressed as a percentage of the total trash in the study area. B) Trash displayed as a percentage of the total risk points digitized in each community.
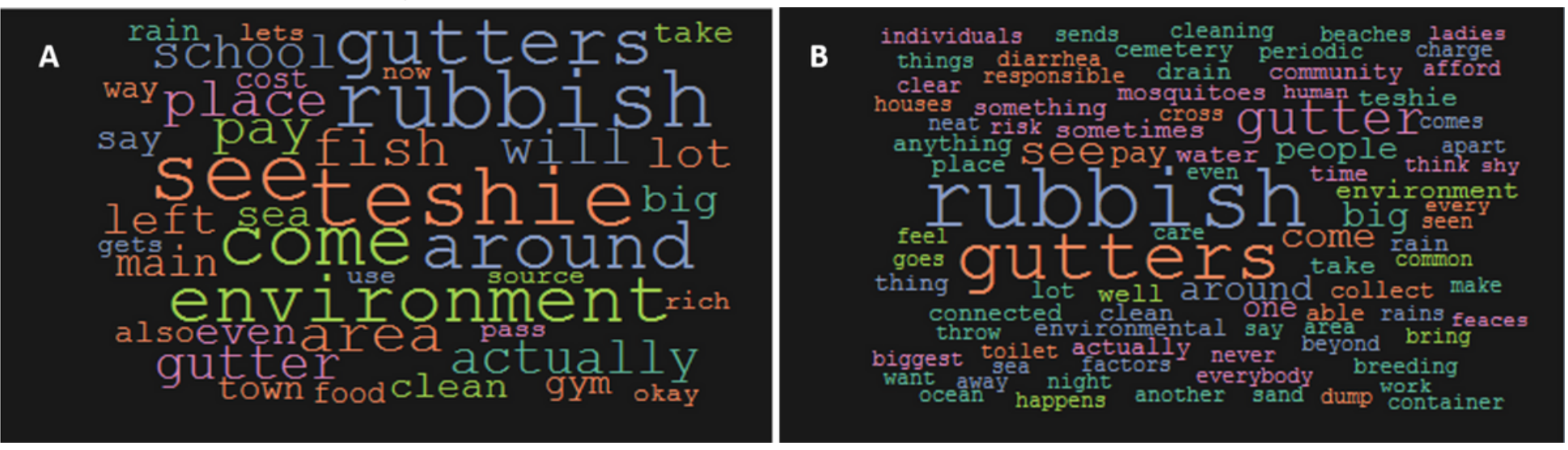

\section{Figure 6}

A typical output from wordmapper: A) displays the most frequently used words by the interviewee, and B) shows the frequency of co-occurring words when comments are selected based on the keyword search 
for "trash" and "gutter" and their synonyms.

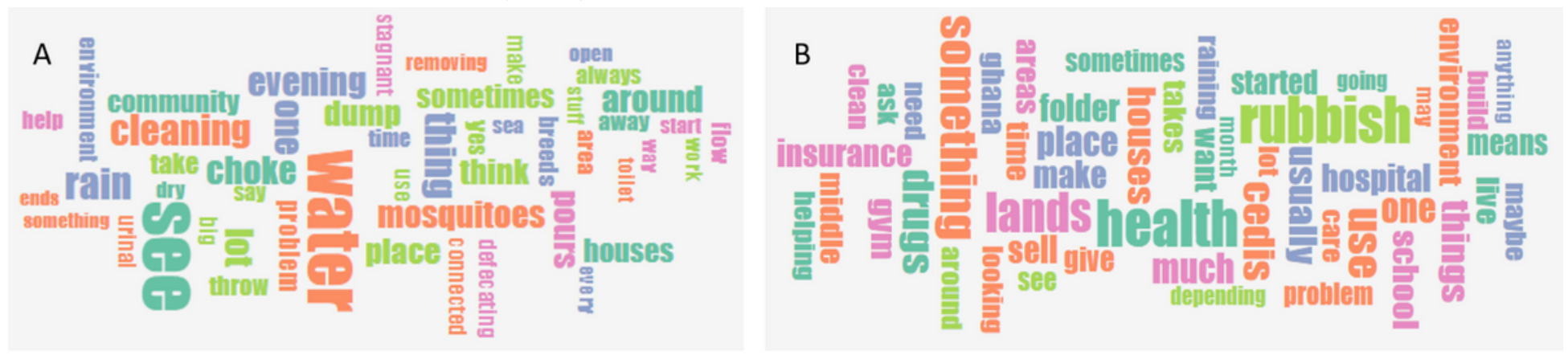

Figure 7

A combined thematic analysis of the twelve SVGs. A) co-occurring word frequencies when Trash or Gutter keywords are used, and B) the same when Poverty keywords and synonyms are employed.
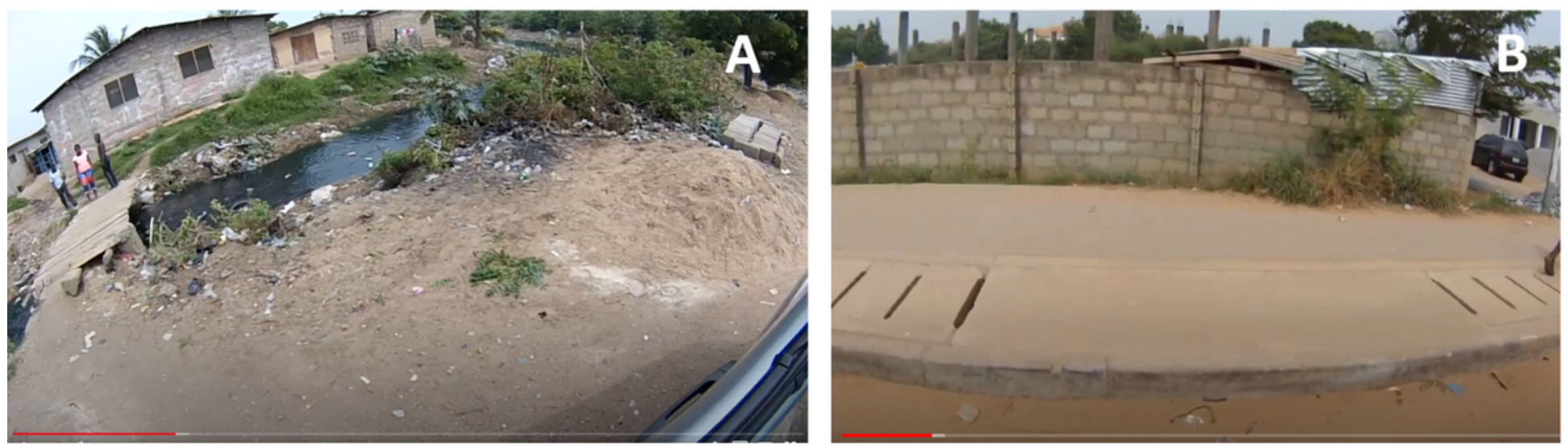

\section{Figure 8}

Comparing similar sized gutters in two different communities. 'A' show an open drain in a lower income community and 'B' shows a drain in a middle-income community. 


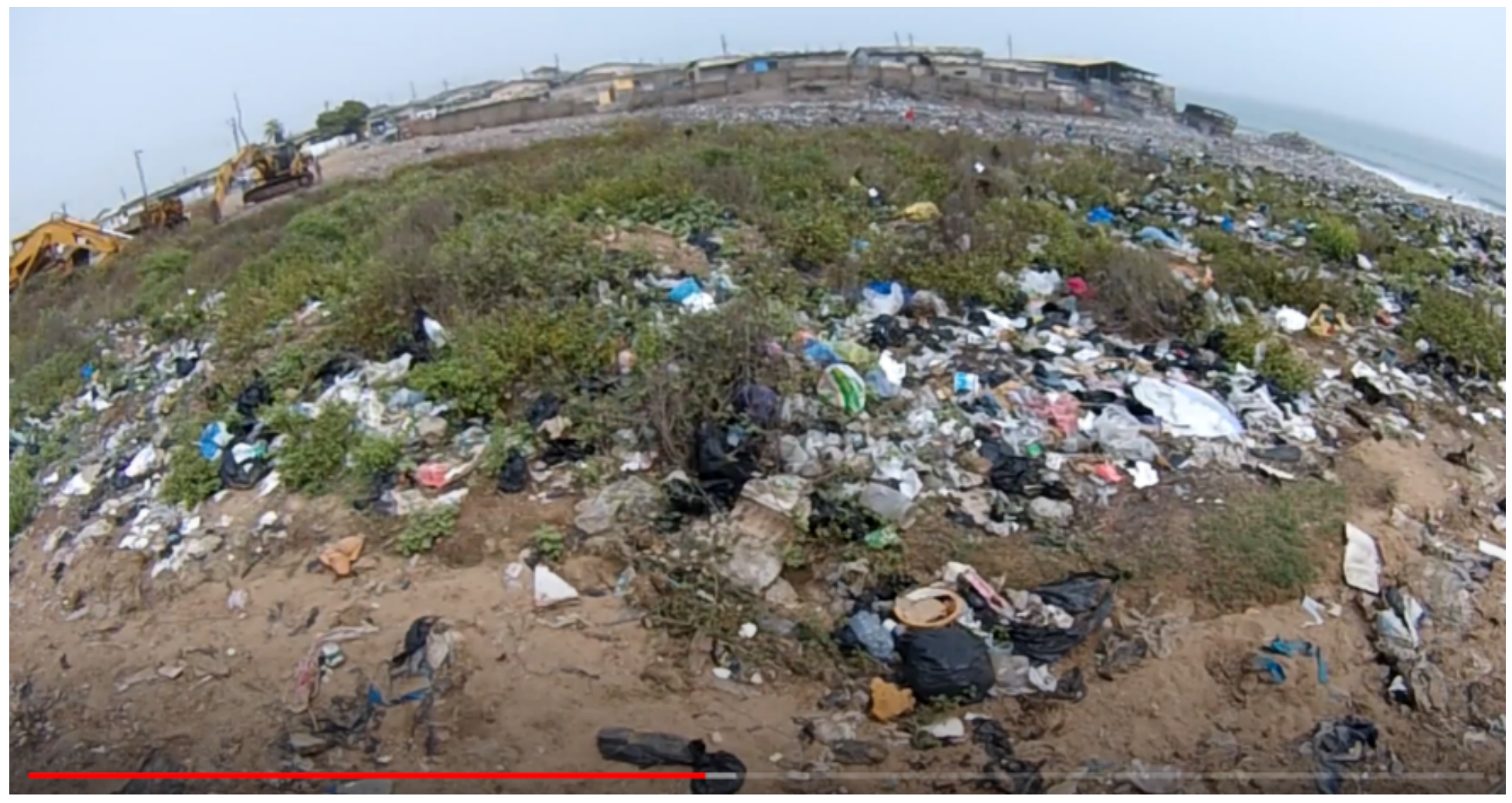

\section{Figure 9}

An illegal dumpsite by the ocean. At the time of data collection, tractors and other machinery (top left corner) had been brought to this site to clear off the filth from the land. The entire land mass was covered in trash and plant overgrowth.

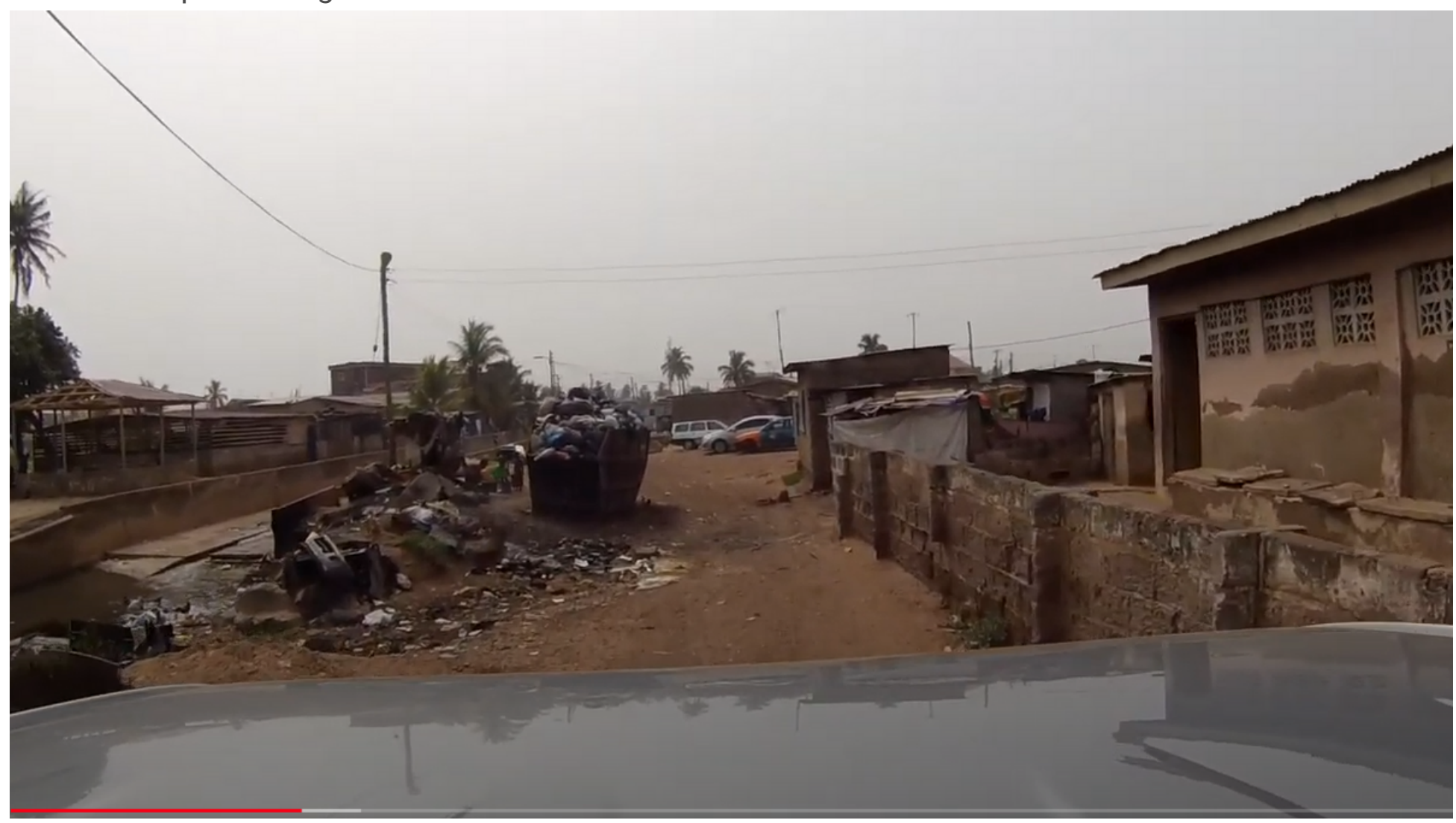




\section{Figure 10}

An example of an overflowing dumpster located close to residential units and an open drain.
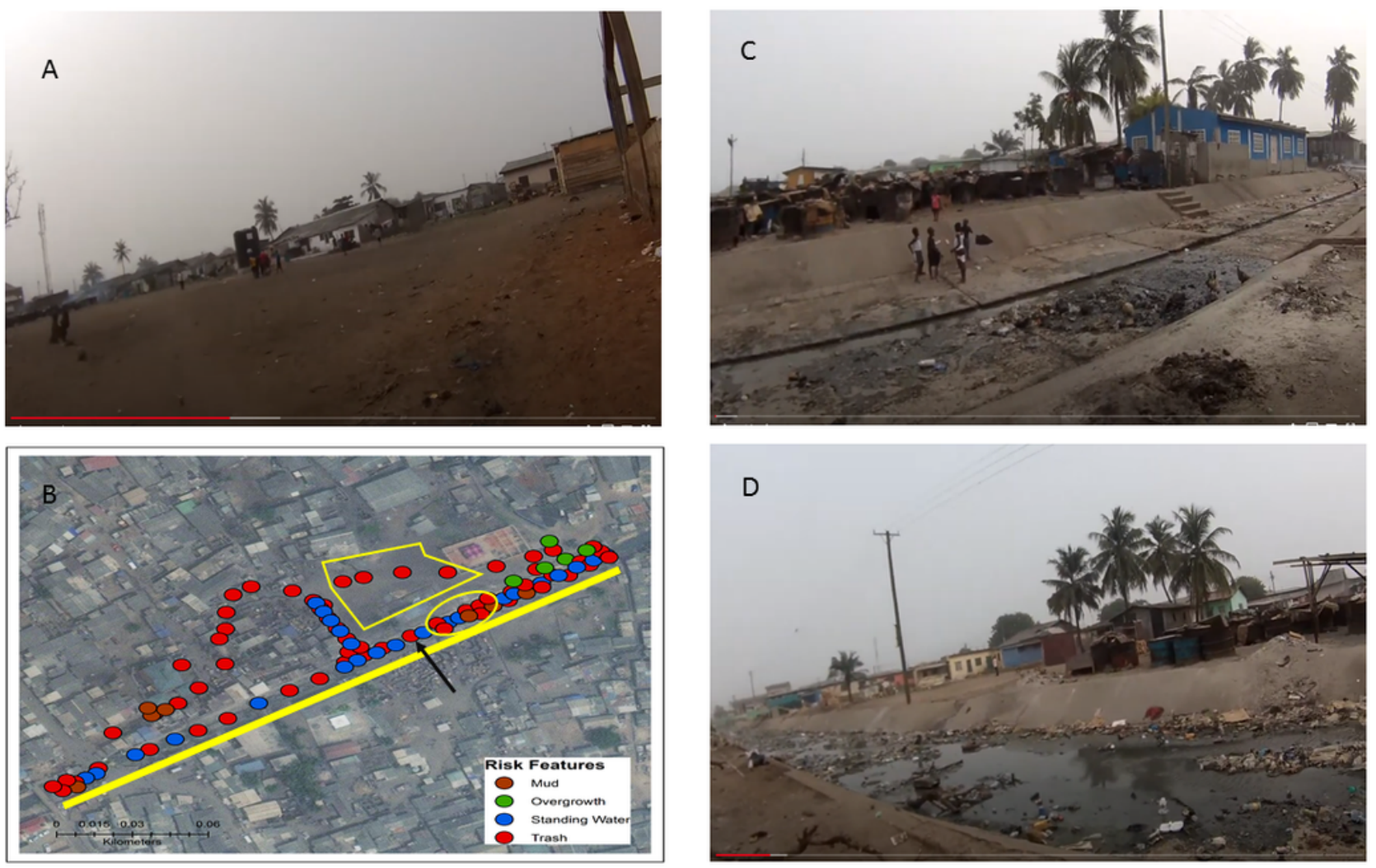

\section{Figure 11}

Children's play space near a drain. A) Shows the park next to the open drain where children gather to play.

B) The SVG walking path. The yellow line and polygon show the position of the drain and park, respectively. The yellow circle shows the location of the most polluted region of the drain which is relatively close to the observed children (black arrow). C) Children playing in the heavily polluted drain located by the black arrow in ' $\mathrm{B}$ '. D) The section where the standing water was deepest and heavily polluted indicated in the yellow oval in ' $\mathrm{B}$ ' 


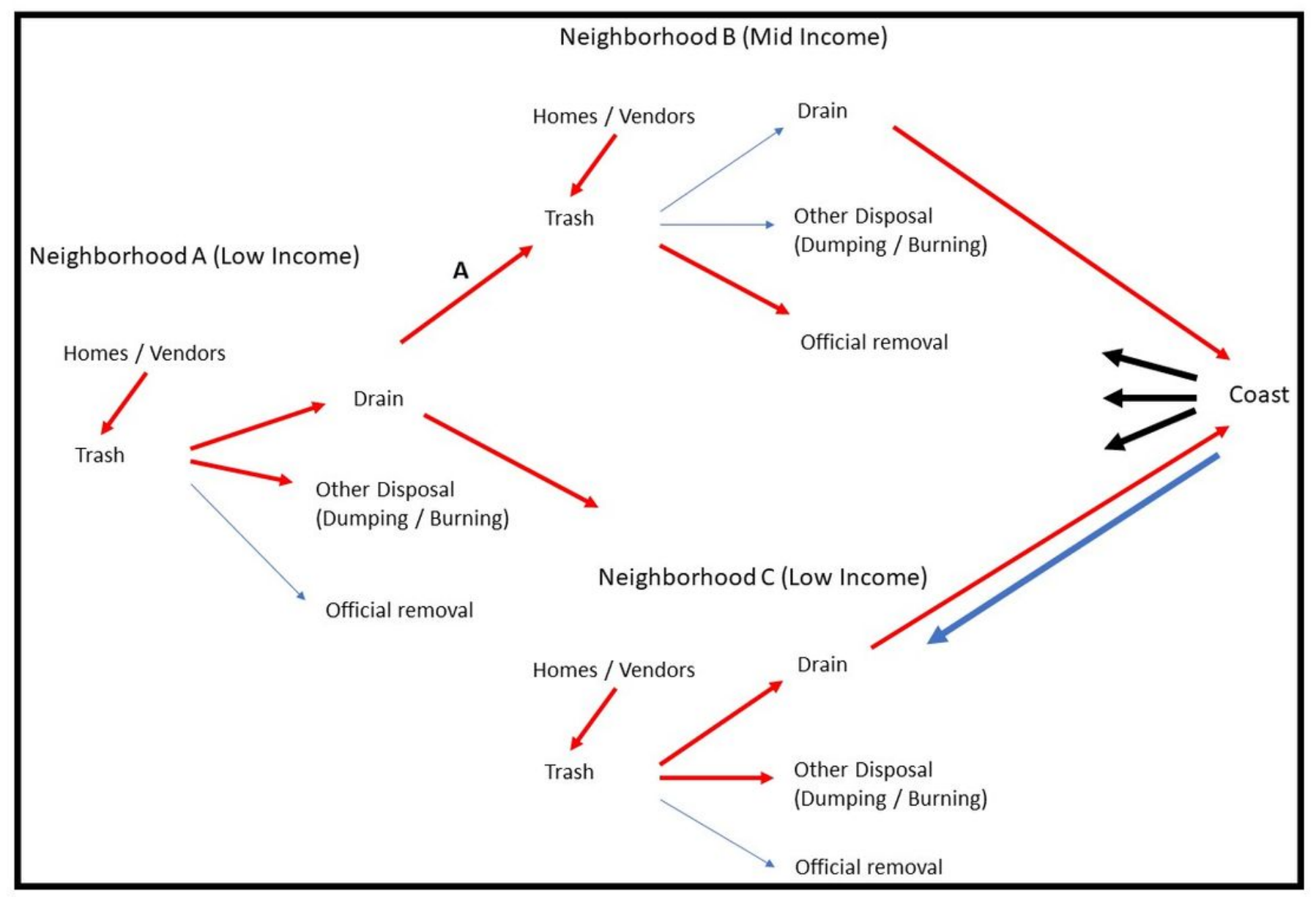

Figure 12

Teshie trash complex. While any of the pathways are possible between neighborhoods, red arrows indicate the more likely interactions leading to the coast. Interactions from the coast occur in the form of tainted fish (black arrows) and tidal flow (blue arrow) leading to localized flooding and water pooling. 